\title{
A Novel Approach for Composite Wear Plate Fabrication by Using Vertical Centrifugal Casting
}

\author{
Mustafa OZKAYA*, Ibrahim Savas DALMIS**, Serdar Osman YILMAZ*** \\ *Tekirdă̆ Namık Kemal University, Çorlu Faculty of Engineering, Mechanical Engineering Department, 59860 , \\ Çorlu-Tekirdăg,Turkey,E-mail:mozkaya@nku.edu.tr \\ **Tekirdă̆ Namık Kemal University, Çorlu Faculty of Engineering, Mechanical Engineering Department, 59860, \\ Çorlu-Tekirdağ, Turkey, E-mail: idalmis@nku.edu.tr \\ ***Tekirdă̆ Namık Kemal University, Çorlu Faculty of Engineering, Mechanical Engineering Department, 59860, \\ Çorlu-Tekirdağ, Turkey, E-mail: oyilmaz@nku.edu.tr
}

crossref http://dx.doi.org/10.5755/j01.mech.24.6.22473

\section{Introduction}

Metal arc welding, sintered carbide tiles bonding, gas tungsten arc (GTA), plasma transferred arc (PTA), thermal spraying, laser cladding modification processes have been widely used in the composite wear plate production of various types of machine parts and tools. To provide a vast variety of mechanical, thermal properties and dimensional accuracy, metal matrix composites (MMCs) are designed. Properties of composites are greatly affected by uniform distribution of precipitates in the metal matrix [1,2].

An extensive research has been conducted over the past three decades on MMCs, and many methods have been proposed for the fabrication of MMCs such as extrusion, casting, powder metallurgy, squeeze casting, and centrifugal casting [3-6]. A composite material has two different components, namely, matrix, and reinforcement. These components have different physical properties. A composite material is a multiphase material in which the properties of both components are combined to obtain better combinations [7]. The properties obtained may be either homogeneous or dispersed in a certain part of the composite material. In composites which are produced by a surface coating method, different properties of superficial layer and internal composite material are obtained [8].

Spheroidal graphite cast iron is used as a matrix material in bearings, camshafts, pistons, and cylinders of machine tools due to its castability, workability, and good mechanical properties. It was stated that the wear behaviour in heavy working conditions was limited and this problem can be solved by modifying the surface properties [9]. This was supported by a study which reported a significant increase in wear resistance which was observed on the piston surface by using SiC for surface modification [10]. Using gray cast iron as matrix and $\mathrm{WC}$ as reinforcement, mass loss was found to be $30.25 \mathrm{mg} / \mathrm{cm}^{2}$ in the unreinforced sample, and $8.33 \mathrm{mg} / \mathrm{cm}^{2}$ in the reinforced sample that also supports the effect of reinforcement on wear resistance [11].

Recently, agricultural machine parts are being hardfaced widely by laser cladding, metal arc welding, sintered carbide tiles bonding, gas tungsten arc welding and plasma tungsten arc welding, thermal spraying processes. MMC Stellite-6 coatings reinforced with tungsten carbide particles was presented by other researchers [12]. The coated layers on B27 boron steel coulter tip was carried out by using laser cladding technology and the investigation of the properties such as microstructure, phase composition, microhardness and wear resistance in the soil were evaluated [13]. Four different electrodes were used for hard facing of leading edge of tiller blades made of high tensile steel by gas tungsten arc welding and the influence of $\mathrm{Cr}$ was studied. Hard faced blades were compared to un-hard faced (standard) blades by field and laboratory tests [14]. Three different thermal spray coatings were used to improve the service life of the tiller blade. Pulsed detonation spray technique was used for deposition of $\mathrm{Cr}_{3} \mathrm{C}_{2}-\mathrm{NiCr}$, Stellite-21 and WC-Co-Cr coating powders on high tensile steel. Wear properties of these coatings were investigated via the pinon-disc mechanism under dry conditions at ambient temperature in accordance with ASTM G-99 standard [15].

Recently, a new type of composite roll ring has been developed by centrifugal casting technique [16-18]. Preheated tungsten carbide particles $\left(\mathrm{WC}_{\mathrm{P}}\right)$ were directly dipped into the liquid iron rotating in a horizontal centrifugal mold, during the process. Due to the centrifugal force and relatively high density of $\mathrm{WC}_{\mathrm{P}}$, particles in the $\mathrm{Fe}-\mathrm{C}$ melt moved towards the outer region, leading to the formation of a surface composite ring part. This method was used to fabricate $\mathrm{SiC}$ particles-reinforced $\mathrm{Al}$ alloy-based composite pistons and here, only a brief overview is given [19-21]. Meanwhile, pretreated SiC particles were weighed and introduced into the slurry. Two kinds of Si particlesreinforced Al-based functionally gradient composite tubes were produced. Primary Si particles alone and primary Si/in situ $\mathrm{Mg}_{2} \mathrm{Si}$ particles jointly were successfully prepared by centrifugal casting and investigated [22].

In the study, the cultivator shovel, which is the most used agricultural tool for all kinds of soil, was studied as the experimental sample. Cultivators are used in field cropping, embossing, weed combat, stubble disruption and fallow processes. This paper presents obtaining a local composite surface layer on the tip of samples by gathering the carbide particles prepared in different sizes during casting. The fabrication approach proposed in this study is based on the vertical centrifugal casting where the reinforcement is placed directly over the predetermined locations in the casting mold.

\section{Experimental details}

The reinforcing carbides were provided with fraction size of approximately $50 \mathrm{~mm}$. Carbide fraction size was reduced to $10-20 \mathrm{~mm}$ in the jaw crusher. The chemical com- 
position of the $\mathrm{M}_{7} \mathrm{C}_{3}$ reinforcing carbide used in the experimental study was given in Table 1 .

Table 1

The chemical composition of reinforcing particles $\left(\mathrm{M}_{7} \mathrm{C}_{3}\right)$

\begin{tabular}{|c|c|c|c|c|c|c|}
\hline Element & $\mathrm{Cr}$ & $\mathrm{Fe}$ & $\mathrm{C}$ & $\mathrm{Si}$ & $\mathrm{P}$ & $\mathrm{S}$ \\
\hline wt. (\%) & 68 & 23 & 7 & 1 & 0.014 & 0.05 \\
\hline
\end{tabular}

Hereafter the grains from the jaw crusher were further reduced to microns with a ball mill and classified by vibrating sieve weighing $3 \mathrm{~g}, 7 \mathrm{~g}, 12 \mathrm{~g}, 20 \mathrm{~g}$ and prepared as indicated in Table 2.

Table 2

Reinforcement powder sizes

\begin{tabular}{|c|c|c|c|c|}
\hline & Size 1. & Size 2. & Size 3. & Size 4. \\
\hline $\begin{array}{c}\text { Size } \\
\text { distribution } \\
(\mu \mathrm{m})\end{array}$ & $<150$ & $150-250$ & $250-500$ & $1000-2000$ \\
\hline
\end{tabular}

The samples were prepared as four different groups according to the reinforcement weight per casting. Each of the groups was classified by particle size. The size and weight of the particles were given in Table 3. The reinforcements were placed locally to the casting mold not in the slurry as mentioned before. Therefore, the amount of reinforcement material was given in grams $(\mathrm{g})$ instead of weight percentages $(\%)$.

Table 3

Powder size and amount

\begin{tabular}{|c|c|c|}
\hline Sample & $\begin{array}{c}\text { The amount of } \\
\text { reinforcements }(\mathrm{g})\end{array}$ & $\begin{array}{c}\text { Reinforcement size } \\
(\mu \mathrm{m})\end{array}$ \\
\hline S1.1 & 3 & $<150$ \\
\hline S1.2 & 3 & $150-250$ \\
\hline S1.3 & 3 & $250-500$ \\
\hline S1.4 & 3 & $1000-2000$ \\
\hline S2.1 & 7 & $<150$ \\
\hline S2.2 & 7 & $150-250$ \\
\hline S2.3 & 7 & $250-500$ \\
\hline S2.4 & 7 & $1000-2000$ \\
\hline S3.1 & 12 & $<150$ \\
\hline S3.2 & 12 & $150-250$ \\
\hline S3.3 & 12 & $250-500$ \\
\hline S3.4 & 12 & $1000-2000$ \\
\hline S4.1 & 20 & $<150$ \\
\hline S4.2 & 20 & $150-250$ \\
\hline S4.3 & 20 & $250-500$ \\
\hline S4.4 & 20 & $1000-2000$ \\
\hline
\end{tabular}

The cultivator shovel shown in Fig. 1 was simulated using the SolidWorks and then the wooden model was produced.

Casting was accomplished using vertical centrifugal casting process (Fig. 2). Because of high mechanical strength and easy to clean from samples resin sand casting was preferred. The pre-weighted amount of pretreated $\mathrm{M}_{7} \mathrm{C}_{3}$ carbide particles of four different fraction size and different amounts, $3 \mathrm{~g}, 7 \mathrm{~g}, 12 \mathrm{~g}$, and $20 \mathrm{~g}$ were placed in the molds. Then the casting process was carried out.

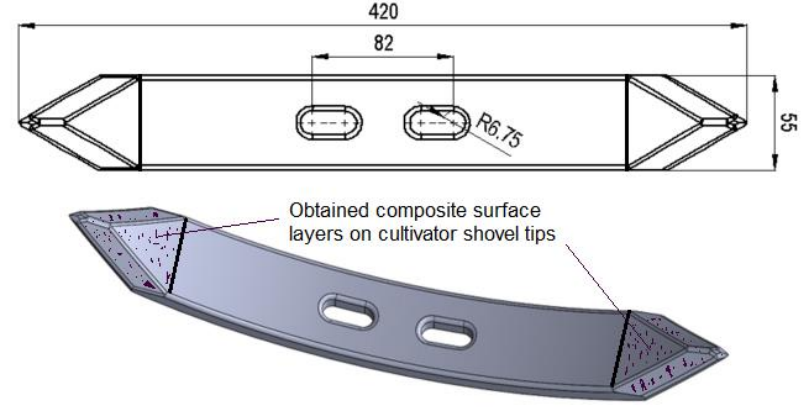

Fig. 1 Drawing of cultivator shovel and specimen used in tests

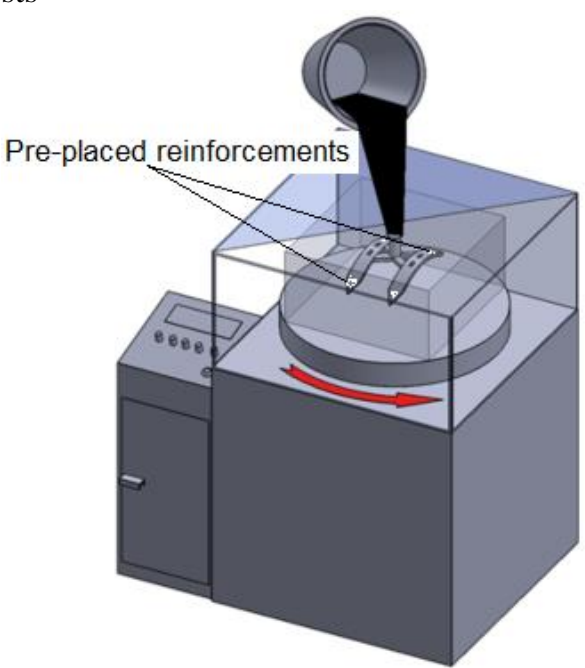

Fig. 2 Vertical centrifugal casting machine

In the casting machine, the operation speed was optimized by changing the speed between $25-500 \mathrm{rpm}$, and $250 \mathrm{rpm}$ was used during casting.

The samples from the cast were cut and specimens were prepared for the abrasive wear test. A self-made wear test machine was used for wear resistance tests which performed on the emery surface with an 80 grit sandpaper covered ring (Fig. 3). The ring was $200 \mathrm{~mm}$ in diameter in the wear test. Each specimen was subjected to a $1 \mathrm{~km}$ wear test under 10, 20, $30 \mathrm{~N}$ load using dry friction conditions.

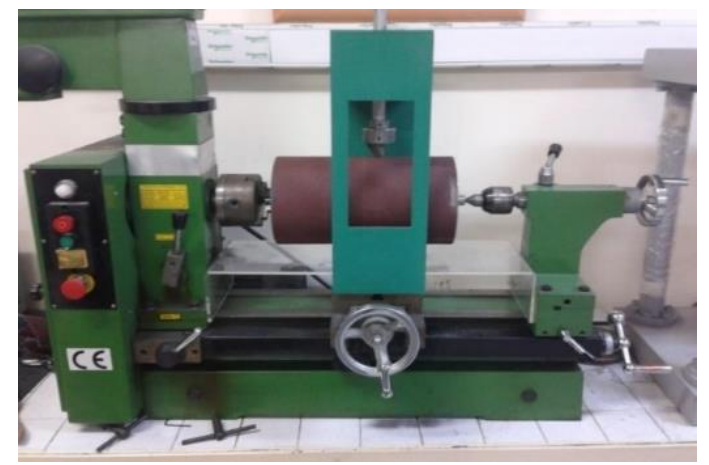

Fig. 3 Wear testing machine

After casting, appropriate samples for metallography were cut from the cast cultivator shovel and prepared. The cut samples were polished with a polishing device and then acid-etched by a mixture of $2 \%$ nitric acid $\left(\mathrm{HNO}_{3}\right) 98 \%$ methyl alcohol $\left(\mathrm{CH}_{3} \mathrm{OH}\right)$. Then, optical microscopy images and microstructure were examined. The surface and crosssectional morphologies of samples were observed by SEM 
(Model JEOL JSM-7001F, Japan). Elemental analysis of the wear plate was examined by energy dispersive spectrometer (EDS). The phase and compounds of the wear plate surfaces were confirmed by X-ray diffraction (Bruker D8 advance Xray diffractometer at $40 \mathrm{kV}, 40 \mathrm{~mA}, \mathrm{Cu} \mathrm{K} \alpha$ radiation source and a wavelength of $\alpha=1.54056 \AA$ ). The microhardness test analysis was used to determine the depth of the wear plate. The hardness analyzes of the samples were performed with $\mathrm{HV}$ (Vikers) hardness scale under a load of $0.5 \mathrm{~kg}$ at $0.5 \mathrm{~mm}$ intervals by QNESS Q10 M microhardness machine.

\section{Results and discussion}

It was seen that the most influencing parameter for carbides distribution was the rotation speed of the casting system. A speed of higher than $250 \mathrm{rpm}$ caused deformation of the mold. Also, the thickness of the composite was reduced as a result of the high speed which caused the accumulation of reinforcement particles near the surface. The low rpm was not enough to distribute the reinforcing powders homogeneously near the surface (Fig. 4). The samples cut from the tip of the cast cultivator shovel were investigated using light optical microscope. The images showed that composite structure was formed in the surface layer of the samples. The rotational speed of the system was studied between 25-250 rpm to optimize most appropriate rpm. It is detected that the optimum speed should be $250 \mathrm{rpm}$ since the distribution of carbides become irregular when the rotational speed exceeded $250 \mathrm{rpm}$ (Fig. 5).
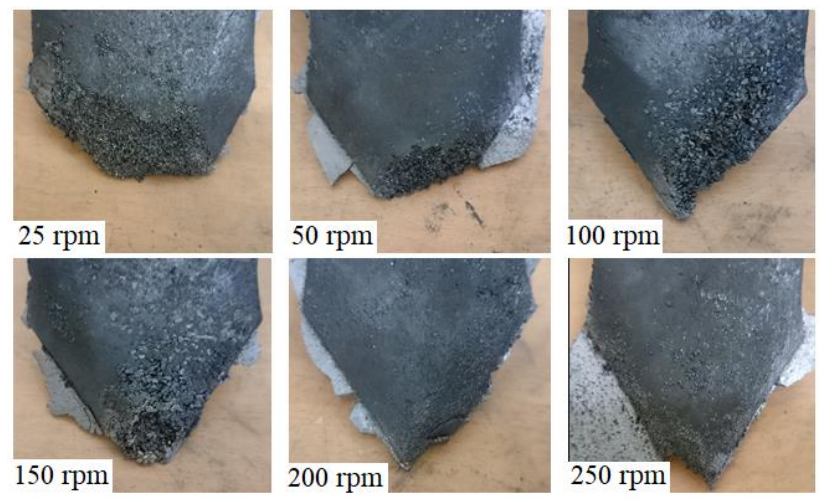

Fig. 4 The fabricated cultivator shovels' tips at different rotation speeds.

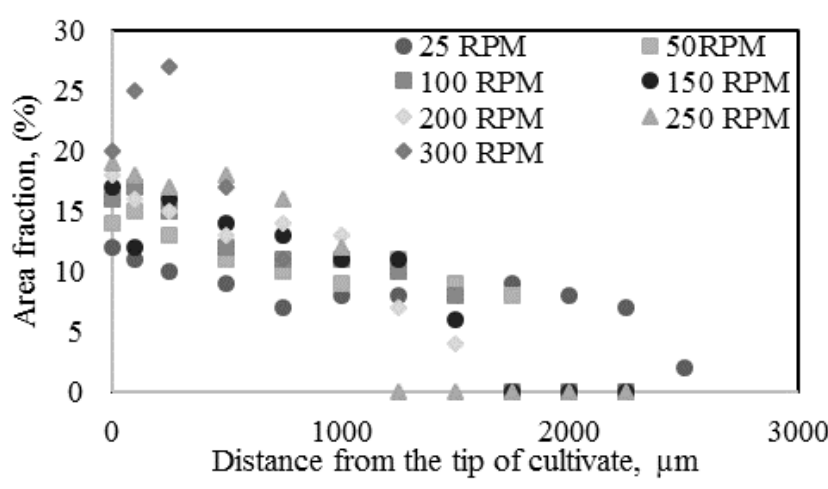

Fig. 5 The distribution of the carbides for rpm of casting

The fabricated wear plate by casting cross-sectional surface was shown in Fig. 6. $\mathrm{M}_{7} \mathrm{C}_{3}$ Carbide particles were homogeneously dispersed near the surface area of the tip regions of the samples. High chromium cast irons are used for wear applications, and from casting of high chromium cast irons it can be seen that carbides $\mathrm{M}_{7} \mathrm{C}_{3}, \mathrm{M}_{23} \mathrm{C}_{6}$ and $\mathrm{M}_{3} \mathrm{C}$ can form in the structure as random distribution where $\mathrm{M}_{23} \mathrm{C}_{6}$ and $\mathrm{M}_{3} \mathrm{C}$ carbides are not preferred [7]. In this study $\mathrm{M}_{7} \mathrm{C}$ carbides were added externally, because from the thermodynamic point of view the formation of unwanted intermetallic and carbides were prevented. During heat treatments of high chromium cast irons unpreferred precipitates can form within the commercial heat treatment temperature range in the alloy. $\mathrm{M}_{23} \mathrm{C}_{6}$ type carbides might only be possible at temperatures under $465^{\circ} \mathrm{C}$ whereas $\mathrm{M}_{3} \mathrm{C}$ can also be expected to precipitate during solidification of cast irons due to the alloying elements. Hence, known amount, concentration and sized $\mathrm{M}_{7} \mathrm{C}_{3}$ carbides were chosen for reinforcing application. This carbide dispersion will not depend on the refinement of the precipitates and their volume fraction.

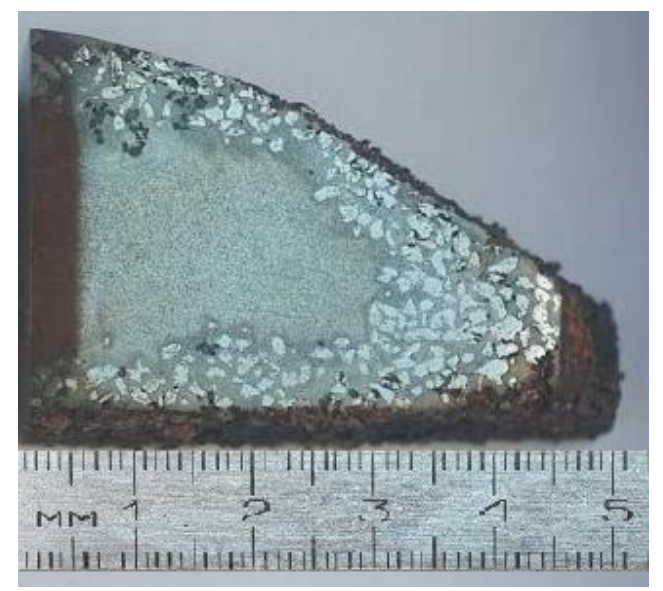

Fig. 6 Cross-section view of a sample

Coating thickness was determined by SEM images. Depending on the amount of reinforcement used and the fraction size, the thickness of the composite texture varied from 300 to $1600 \mu \mathrm{m}$. When the amount of reinforcement was increased to $20 \mathrm{~g}$, the coating thickness increased up to $1600 \mu \mathrm{m}$. However, as the amount of reinforcement increased, the amount of void also increased in the structure. Thus cracks and damages occurred and the surface quality decreased. In the S4.2 sample, the coating thickness was approximately $1600 \mu \mathrm{m}$ as shown in the SEM image (Fig. 7).

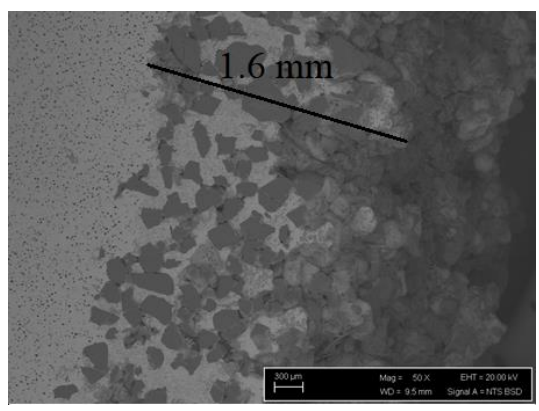

Fig. 7 SEM image of sample S4.2 coded sample

Applying the reinforcement with an amount of $7 \mathrm{~g}$, the homogeneous distribution of carbides in the surface, the surface roughness and the void ratio in the composite texture were optimized. The increase of the reinforcement fraction size showed that the thickness of the composite texture increased. It was determined that the particles lumped when 
the size of the reinforcement was below $250 \mu \mathrm{m}$ and easily dissolved in liquid metal. Taking into account the amount and the size of reinforcement, the ideal composite texture was obtained in the third S3 group from sample S3.3 in terms of the reinforcement distribution at the sample surface, the surface void, and the adhesion characteristics between the reinforcing matrix. In the S3.3 sample, the coating thickness was approximately $1200 \mu \mathrm{m}$ as shown in the SEM image (Fig. 8).

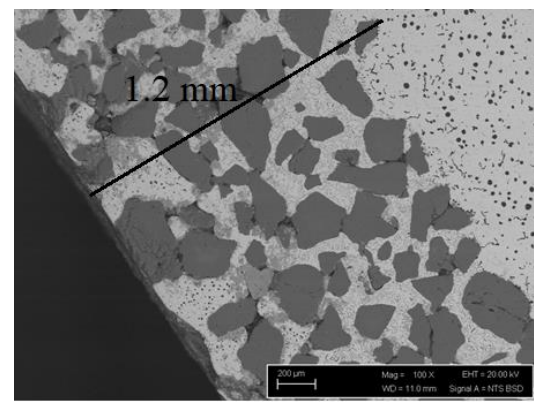

Fig. 8 SEM image of S3.3 coded sample

The SEM image taken from the sample S2.4 (Fig. 9) shows that the coating thickness formed on the surface was approximately $1000 \mu \mathrm{m}$. As seen from microstructure images, liquid metal wrapped reinforcement particles hence gaps and defects were eliminated on the interface.

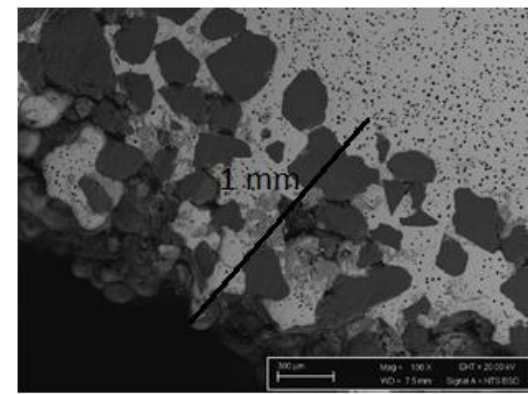

Fig. 9 SEM image of sample S2.4 coded sample

Spheroidal graphite cast iron was used as the matrix material. However, as seen in Fig. 10, the expected graphite in the spheroid form in the reinforced surface region was formed as lamellar. The $\mathrm{M}_{7} \mathrm{C}_{3}$ car-bides speeded up the cooling of the melt during solidification and prevented the globalization of the graphite [12]. During solidification of nodule graphite cast iron, the cooling gradient had an important role in shaping the graphite. Reinforcements in this region created the effect of chilling to prevent the spheroidization of graphite.

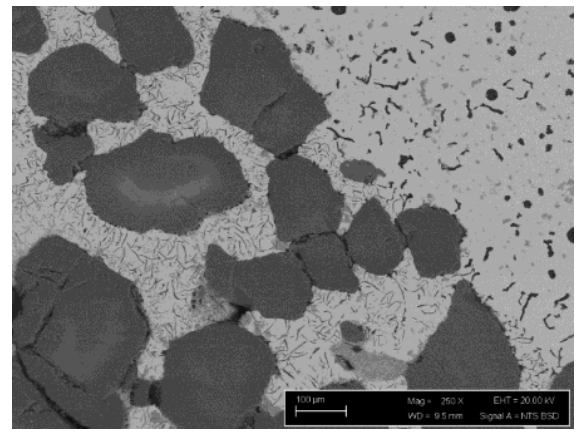

Fig. 10 SEM image of S3.3 coded sample
The microhardness test results taken from the matrix of the samples are shown in Table 4. The hardness test of the test specimens was performed on the cross-sectional surface. From the obtained results, it can be said that $\mathrm{M}_{7} \mathrm{C}_{3}$ carbide had the greatest values, the cast iron which was the matrix material had the medium values and the spheroidal graphite nodules had the lowest values [23]. The presence of the carbides in the structure increased cooling rate. Thus the shape and the amount of graphite with the pearlite phase were modified (Fig. 10). It was aimed to detect the hardness changes of the modified microstructure by microhardness distribution. From the Table 4, it can be said that the increase of the carbide concentration also increased the matrix hardness which can be explained as the increase the rate of the pearlitic structure in the matrix.

Table 4

Microhardness analysis

\begin{tabular}{|l|l|l|l|}
\hline \multicolumn{4}{|l|}{ Microhardness analysis of samples (HV) } \\
\hline S1.2 & S2.2 & S3.2 & S4.2 \\
\hline 185 & 272 & 222 & 234 \\
\hline 282 & 242 & 280 & 290 \\
\hline 210 & 290 & 201 & 452 \\
\hline 263 & 351 & 222 & 627 \\
\hline 282 & 639 & 255 & 906 \\
\hline 417 & 695 & 359 & 1904 \\
\hline 358 & 974 & 398 & 834 \\
\hline 439 & 1080 & 393 & 639 \\
\hline 471 & 1447 & 1560 & 1939 \\
\hline 1573 & 750 & 1842 & 1785 \\
\hline 1181 & 843 & 222 & 1300 \\
\hline
\end{tabular}

The XRD analysis of sample S2.4 is shown in Fig. 11.

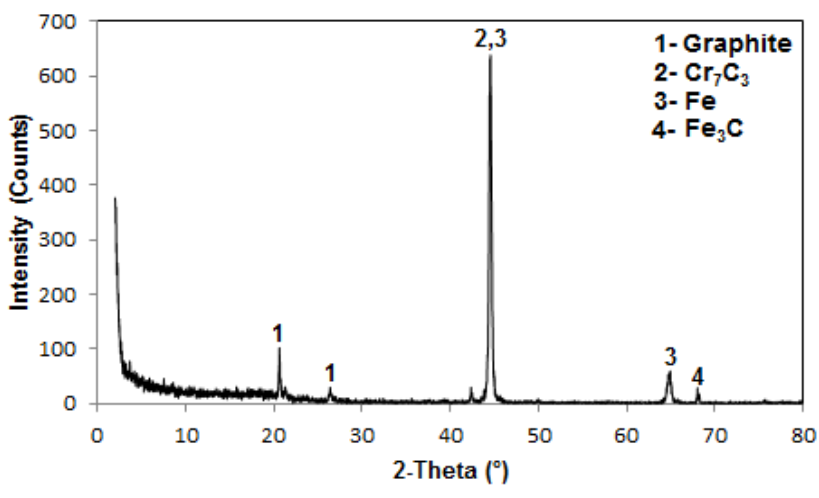

Fig. 11 XRD result of s24 sample

The XRD result showed that the reinforcement in the structure was $\mathrm{M}_{7} \mathrm{C}_{3}$ carbide and the matrix consists of graphite with ferrite and pearlite. EDS analysis were taken from the surface. XRD analyses were compared with the EDS results obtained from reinforcement and matrix (Figs. 12-13). These results were in harmony with the formation of graphite in the near surface region of the coating as well as the addition of externally involved carbide reinforcements.

The wear test results of the samples were given in Fig. 14. The wear resistance of the reinforced wear plate samples under loads of 10, 20 and $30 \mathrm{~N}$ was determined. Depending on the applied load, the wear on the surface 
showed a linear tendency. The amount of wearing in the specimens were increased linearly. The rate of wear due to reinforcement ratio and reinforcement size were investigated for each group (Fig. 14). As explained in experimental procedure, depending on the amount of the particulate addition the samples grouped from S1 to S4. When the wear rates were examined, it was seen that the wear rate decreased on increasing of fraction size of carbides. As seen in Fig. 14, the wear curves of the samples with low fraction reinforcement size have greater slopes than the wear curves of the samples with large fraction reinforcement size. The specimens with large reinforcements were not affected by the increased load as much as the specimens with small reinforcement sizes. It was seen from the samples between $\mathrm{S} 1$ to $\mathrm{S} 4$ group, the ideal reinforcement amount was obtained from groups S2.4 and S3.4 which have been reinforced with 7 to $12 \mathrm{~g}$ particulate (Figs. 14, b-c). It was observed that the increase in reinforcements over $12 \mathrm{~g}$ increased the wear rate (Fig. 14, d). The reason for this was thought to be that the rotational speed could not be enough when the amount of the reinforcement material was increased further.
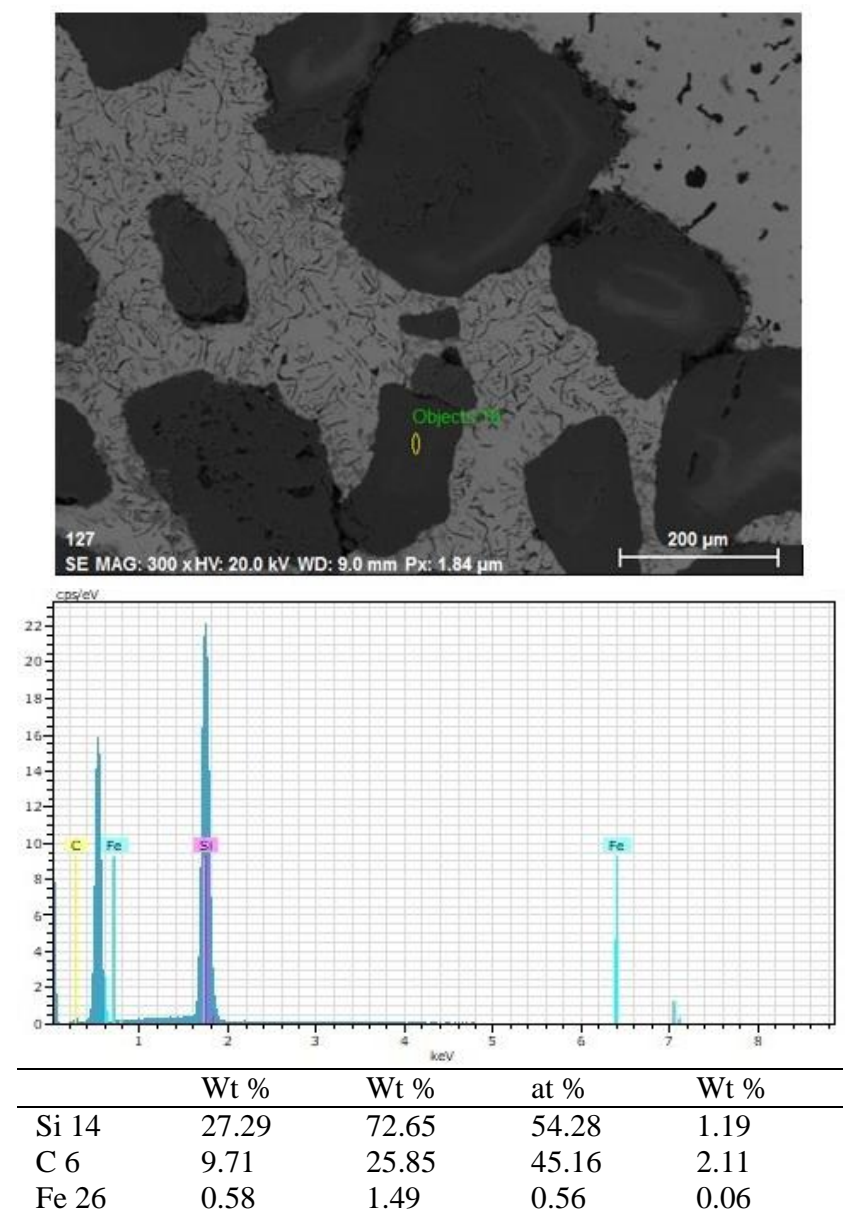

Fig. 12 EDS results obtained from the reinforcement

Fig. 14 presents the correlation between wear rate and the load of reinforced specimens. It was observed that for each group, the specimen S2.4 had the lowest wear rate. The composites' tribological behavior was tried to determine by the microstructural characteristics of the material and by the type of loading-contact situation. It was supposed that the wear resistance of the specimen S2 was high due to the size of the carbides in it. It was apparent that the carbide reinforcements led to a significant reduction in wear rate of the composites throughout abrasive wear. Furthermore, the wear rate was reduced by the increase of the carbides ratio in the matrix which was demonstrated by the abrasive tests. Nevertheless, the wear resistance of the specimens was reduced after a specified ratio (Fig. 14b). It was considered that the reduction of wear rate was significantly determined by the decline of the concentration of carbides, and was caused by the distribution of the particles in the matrix. The surface would be plastically deformed or cut by the abrasive particle based on the size of the abrasive grit. Thus, the size rate between reinforcement and grit was significant. When the wear particles become smoother or the particle size reduces, the transition to delamination wear occurs without interruption by the wear mechanism. Besides, there was a critical particle size. For this study it was tested the size interval of 100-2000 $\mu \mathrm{m}$. An increase in the wear rate with the applied load was observed up to a critical particle size (1000 $\mu \mathrm{m})$. Beyond the critical values, the wear rate was mainly independent on the particle size and the load. Moreover, this critical value was affected by the hardness dissimilarities between the carbides and the material of the matrix [2429]. Therefore, for the purpose of increasing the critical load up to the point where wear alters from micro-cutting to micro-cracking, the particles with various hardness, toughness, and structures were used as a reinforcement material in the specimen S2. A strong correlation with the rpm and wear rate of the specimens was observed. Rotational speed affected the thickness of the coating and distribution of carbides.

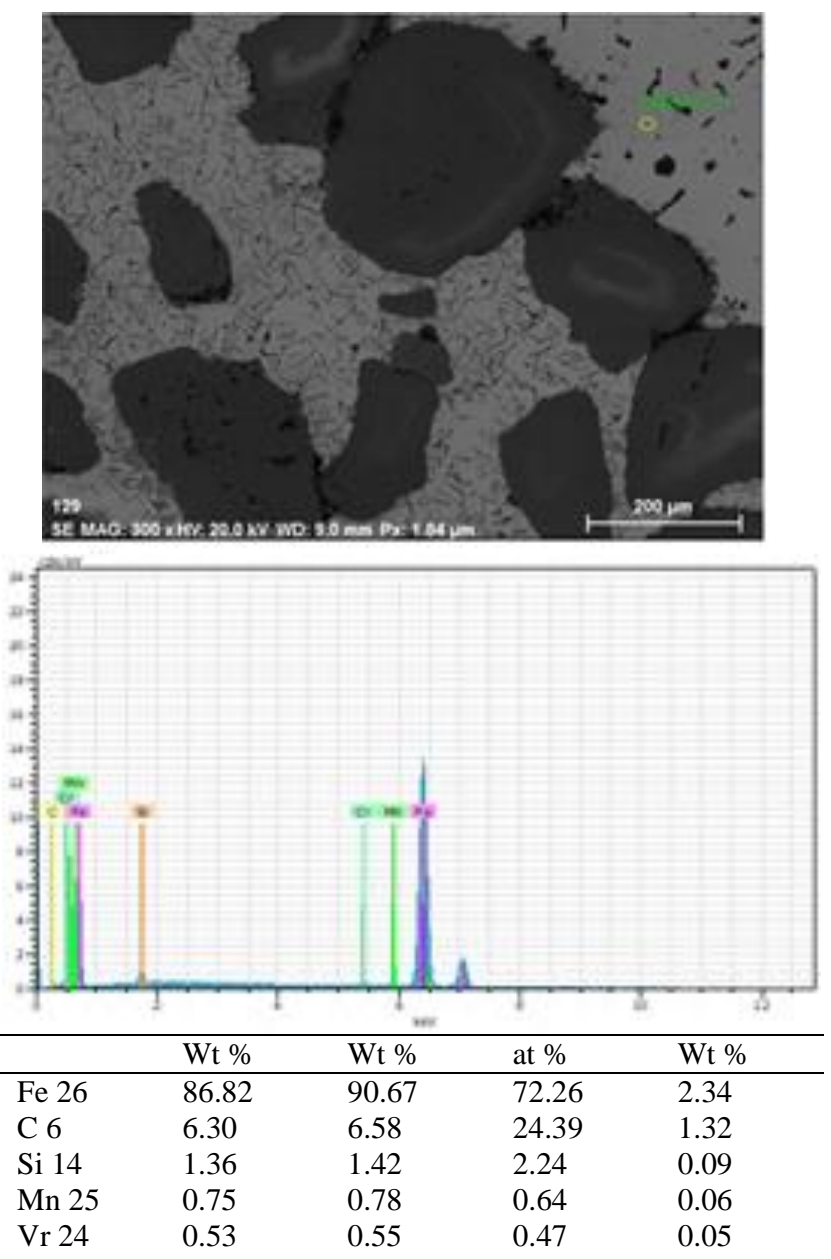

Fig. 13 EDS results obtained from the Matrix 

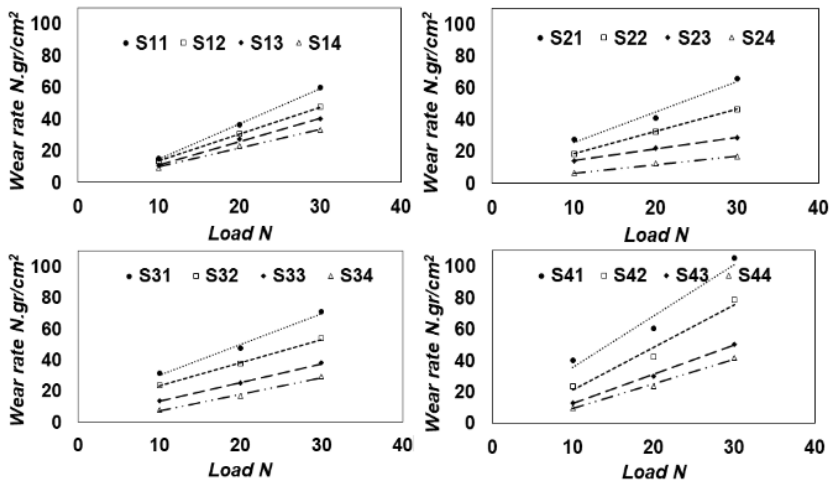

Fig. 14 Wear rate-load relations, a) group $\mathrm{S} 1$, b) group $\mathrm{S} 2$, c) group $\mathrm{S} 3, \mathrm{~d}$ ) group $\mathrm{S} 4$

The size of the particles and the applied load during wear determined the size of the plastically deformed region beneath the worn surface throughout abrasive wear [30]. There was the linear relationship among the total depth of the plastic deformation, the applied load and the particle distribution. The association between the amount of reinforcement material and wear rate was presented in Fig. 14, a. It can be expressed that the wear rate was significantly affected by the amount of carbide and carbide size. A microstructure with increased carbide concentration was created by the increase in the homogenization treatment cooling time.

\section{Conclusions}

This paper presents a practical application of wear plate fabrication together with the results of laboratory tests. Vertical centrifugal casting technology seems to be suitable for application of the type of products that require high surface wear resistance. General conclusions are as follows.

In the study, composite wear plates were produced with vertical centrifugal casting.

The average thickness of the composite formed on the sample surface was found to be 1000-1200 $\mu \mathrm{m}$.

It was determined that depending on the carbide particles amount and size, the wear resistance of the wear plates increased at different ratios, and the best result was obtained from the sample having $7 \mathrm{~g}$ particulate and 100$2000 \mu \mathrm{m}$ in size.

In the areas where $\mathrm{M}_{7} \mathrm{C}_{3}$ carbide particles existed, the cooling speed of the matrix was increased and the globalization of the graphite in the matrix was prevented for spherical cast iron matrix.

The cultivator shovel was produced by using spheroidal graphite cast iron as a matrix and $\mathrm{M}_{7} \mathrm{C}_{3}$ as a reinforcement material. For further studies steel matrix can be tested.

The correlation between the rotational speed and carbide distribution shows that it is possible to work up to $250 \mathrm{rpm}$. The types of casting molds, the amount of the particles and the rotational speed can be further studied.

Experiments can also be done for different material constructions at different densities.

\section{Acknowledgments}

This work was supported by Research Fund of the Tekirdağ Namık Kemal University. Project Number: NKUBAP.00.17.AR.13.18

\section{References}

1. Naher, S.; Brabazon, D.; Looney, L. 2007. Computational and experimental analysis of particulate distribution during Al-SiC MMC fabrication, Composites Part A: Applied Science and Manufacturing 38: 719-729. http://dx.doi.org/10.1016/j.compositesa.2006.09.009.

2. Kai, W.A.N.G.; Xue, H.S.; Zou, M.H.; Liu, C.M. 2009. Microstructural characteristics and properties in centrifugal casting of SiCp/Z1104 composite, Transactions of Nonferrous Metals Society of China 19: 1410-1415. https://doi.org/10.1016/S1003-6326(09)60042-X.

3. Karamis, M. B.; Tasdemirci, A.; Nair, F. 2003. Failure and tribological behavior of the AA5083 and AA6063 composites reinforced by $\mathrm{SiC}$ particles under ballistic impact, Composites Part A: Applied Science and Manufacturing 34: 217-226.

https://doi.org/10.1016/S1359-835X(03)00024-1.

4. Karamıs, M. B.; Nair, F. 2008. Effects of reinforcement particle size in MMCs on extrusion die wear, Wear 265: $1741-1750$.

https://doi.org/10.1016/j.wear.2008.04.044.

5. Thomas, M.P.; King, J.E. 1994. Quench sensitivity of $2124 \mathrm{Al}$ alloy and $\mathrm{Al} / \mathrm{SiCp}$ metal matrix composite, Scripta Metallurgica et Materialia 31: 209-214. https://doi.org/10.1016/0956-716X(94)90176-7.

6. Karamış, M. B.; Cerit, A. A.; Selçuk, B.; Nair, F. 2012. The effects of different ceramics size and volume fraction on wear behavior of $\mathrm{Al}$ matrix composites (for automobile cam material), Wear 289: 73-81. https://doi.org/10.1016/j.wear.2012.04.012.

7. Callister Jr, W. D.; Rethwisch, D. G. 2011. Fundamentals of materials science and engineering: an integrated approach, 8th Edition, John Wiley \& Sons 144, 578.

ISBN-13: 978-0-471-73696-7.

8. Lin, X.; Liu, C.; Xiao, H. 2013. Fabrication of Al-Si$\mathrm{Mg}$ functionally graded materials tube reinforced with in situ $\mathrm{Si} / \mathrm{Mg}_{2} \mathrm{Si}$ particles by centrifugal casting, Composites: Part B 45: 8-21.

https://doi.org/10.1016/j.compositesb.2012.09.001.

9. Jeshvaghani, R. A.; Jaberzadeh, M.; Zohdi, H.; Shamanian, M. 2014. Microstructural study and wear behavior of ductile iron surface alloyed by inconel 617 , Material and Design 54: 491-497.

https://doi.org/10.1016/j.matdes.2013.08.059.

10. Huang, X.; Liu, C.; Lv, X.; Liu, G.; Li, F. 2011. Aluminum alloy pistons reinforced with $\mathrm{SiC}$ fabricated by centrifugal casting, Journal of Material Processing Technology 211: 1540-1546.

https://doi.org/10.1016/j.jmatprotec.2011.04.006.

11. Niu, L.; Hojamberdiev, M.; Xu, Y. 2010. Preparation of in situ-formed $\mathrm{WC} / \mathrm{Fe}$ composite on gray cast iron substrate by a centrifugal casting process, Journal of Material Processing Technology 210: 1986-1990. https://doi.org/10.1016/j.jmatprotec.2010.07.013.

12. Peng, Y.C.; Jin, H.J.; Liu, J.H.; Li, G.L. 2012. Influence of cooling rate on the microstructure and properties of a new wear resistant carbide austempered ductile iron (CADI), Materials Characterization 72: 53-58. https://doi.org/10.1016/j.matchar.2012.07.006. 
13. Bartkowski, D.; Bartkowska, A. 2017. Wear resistance in the soil of Stellite-6/WC coatings produced using laser cladding method. International Journal of Refractory Metals and Hard Materials 64: 20-26. https://doi.org/10.1016/j.ijrmhm.2016.12.013.

14. Kang, A.S.; Cheema, G.S.; Singla, S. 2014. Wear behavior of hardfacings on rotary tiller blades. Procedia Engineering 97: 1442-1451.

https://doi.org/10.1016/j.proeng.2014.12.426.

15. Kang, A. S.; Grewal, J. S.; Cheema, G. S. 2017. Effect of thermal spray coatings on wear behavior of high tensile steel applicable for tiller blades. Materials Today: Proceedings 4: 95-103. https://doi.org/10.1016/j.matpr.2017.01.001.

16. Song, Y. P.; Yu, H.; Mao, X. M. 2008. Wear behavior of $\mathrm{WCP} / \mathrm{Fe}-\mathrm{C}$ composites under highspeed dry sliding, Journal of Materials Science 43: 2686-2692. https://doi.org/10.1007/s10853-007-2415-y.

17.Song, Y.P.; Yu, H.; He, J.G.; Wang, H.G. 2008. Elevated temperature sliding wear behavior of $\mathrm{WC}_{\mathrm{P}}$ reinforced ferrous matrix composites, Journal of Materials Science 43: 7115-7120. https://doi.org/10.1007/s10853-008-3027-x.

18. Song, Y.; Wang, H. 2012. High speed sliding wear behavior of recycled $\mathrm{WC}_{\mathrm{P}}$-reinforced ferrous matrix composites fabricated by centrifugal cast. Wear 276: 105110.

https://doi.org/10.1016/j.wear.2011.12.017.

19. Nai, S. M. L.; Gupta, M. 2002. Influence of stirring speed on the synthesis of $\mathrm{Al} / \mathrm{SiC}$-based functionally gradient materials. Composite Structures 57: 227-233. https://doi.org/10.1016/S0263-8223(02)00089-2.

20. Balasivanandha Prabu, S.; Karunamoorthy, L.; Kathiresan, S.; Mohan, B. 2006. Influence of stirring speed and stirring time on distribution of particles in cast metal matrix composite. Journal of Materials Processing Technology 171: 268-273. https://doi.org/10.1016/j.jmatprotec.2005.06.071.

21. Huang, X.; Liu, C.; Lv, X.; Liu, G.; Li, F. 2011. Aluminum alloy pistons reinforced with $\mathrm{SiC}$ fabricated by centrifugal casting. Journal of Materials Processing Technology 211: 1540-1546. https://doi.org/10.1016/j.jmatprotec.2011.04.006.

22. Zhai, Y.B.; Liu, C.M.; Kai, W.; Zou, M.H.; Yong, X. 2010. Characteristics of two Al-based functionally gradient composites reinforced by primary Si particles and $\mathrm{Si} / \mathrm{in}$ situ $\mathrm{Mg} 2 \mathrm{Si}$ particles in centrifugal casting. Transactions of Nonferrous Metals Society of China 20: 361370. https://doi.org/10.1016/S1003-6326(09)60147-3.

23. Rajan, T. P. D.; Pillai, R. M.; Pai, B. C. 2010. Characterization of centrifugal cast functionally graded aluminum-silicon carbide metal matrix composites, Material Characterization 61: 923-928. https://doi.org/10.1016/j.matchar.2010.06.002.

24. Wang, J.; Xiong, J.; Fan, H.; Yang, H.S.; Liu, H.H.; Shen, B.L. 2009. Effects of high temperature and cryogenic treatment on the microstructure and abrasion resistance of a high chromium cast iron. Journal of Materials Processing Technology 209: 3236-3240. https://doi.org/10.1016/j.jmatprotec.2008.07.035.

25. Tabrett, C. P.; Sare, I. R. 1998. Effect of high temperature and sub-ambient treatments on the matrix structure and abrasion resistance of a high-chromium white iron. Scripta Materialia 38: 1747-1753.

https://doi.org/10.1016/S1359-6462(98)00118-3.

26. Darwin, J. D.; Lal, D. M.; Nagarajan, G. 2008. Optimization of cryogenic treatment to maximize the wear resistance of $18 \% \mathrm{Cr}$ martensitic stainless steel by Taguchi method. Journal of Materials Processing Technology 195: 241-247.

https://doi.org/10.1016/j.jmatprotec.2007.05.005.

27. Gill, S. S.; Singh, R.; Singh, H.; Singh, J. 2009. Wear behaviour of cryogenically treated tungsten carbide inserts under dry and wet turning conditions. International Journal of Machine Tools and Manufacture 49: 256-260. https://doi.org/10.1016/j.ijmachtools.2008.11.001.

28. Liu, H. H.; Wang, J.; Shen, B. L.; Yang, H. S.; Gao, S. J.; Huang, S. J. 2007. Effects of deep cryogenic treatment on property of $3 \mathrm{Cr} 13 \mathrm{Mo} 1 \mathrm{~V} 1.5$ high chromium cast iron. Materials \& Design 28: 1059-1064. https://doi.org/10.1016/j.matdes.2005.09.007.

29. Yang, H. S.; Wang, J.; Shen, B. L.; Liu, H. H.; Gao, S. J.; Huang, S. J. 2006. Effect of cryogenic treatment on the matrix structure and abrasion resistance of white cast iron subjected to destabilization treatment. Wear 261: $1150-1154$. https://doi.org/10.1016/j.wear.2006.03.021.

30. Moore, M. A.; Douthwaite, R. M. 1976. Plastic deformation below worn surfaces. Metallurgical Transactions A 7: 1833-1839. https://doi.org/10.1007/BF02659813.

\section{Ozkaya, I. S. Dalmis, S. O. Yilmaz}

\section{A NOVEL APPROACH FOR COMPOSITE WEAR PLATE FABRICATION BY USING VERTICAL CENTRIFUGAL CASTING}

S u m m a r y

A novel approach of wear plate fabrication by vertical centrifugal casting was proposed and demonstrated in this paper. Wear plates were reinforced by the addition of $\mathrm{M}_{7} \mathrm{C}_{3}$ carbide particles during vertical centrifugal casting. The effect of size and the weight ratio of the carbide particles on wear resistance were investigated. The prepared carbide particles were used as 150-2000 $\mu \mathrm{m}$ in size and 3-20 g in weight per casting. Spheroidal graphite cast iron has been used as matrix material. During casting, the machine was operated at $250 \mathrm{rpm}$. The carbide powders have been formed a local coating of $300-1600 \mu \mathrm{m}$ thickness on the sample tip surfaces. The average thickness of the composite formed on the sample surface was found to be 1000-1200 $\mu \mathrm{m}$. The elemental distributions were analyzed by EDS. XRD and XPS were used for characterizing the phase structures. The samples were subjected to a "block on ring" abrasive wear test. It has been observed that the abrasion resistance of samples having a powder size of 1000-2000 $\mu \mathrm{m}$ has the highest abrasion resistance.

Keywords: wear plate, vertical centrifugal casting, metal matrix composites, particle reinforcement, abrasive wear.

Received October 31, 2018 Accepted December 12, 2018 